Int. J. Electrochem. Sci., 15 (2020) 1949 - 1963

International Journal of

ELECTROCHEMICAL

SCIENCE

WWW.electrochemsci.org

\title{
Three-dimensional Hierarchical Structure NiFe Layered Double Hydroxides Nanosheets Based on Carbon Cloth for High Performance Non-Enzymatic Glucose Detection
}

\author{
Dandan Song ${ }^{l}$, Lili Wang ${ }^{l, *}$, Bing Wang ${ }^{1, *}$, Jianguo $\mathrm{Yu}^{l}$, Yanting $\mathrm{Li}^{2}$, Yuning $Q \mathrm{u}^{l}$, \\ Cunpeng Duan ${ }^{2}$, Yuying Yang ${ }^{1}$, Xueli Miao ${ }^{2}$ \\ ${ }^{1}$ State Key Laboratory of Separation Membranes and Membrane Processes, School of Chemistry and \\ Chemical Engineering, Tiangong University, 399 Binshui West Road, Tianjin 300387, P. R. China \\ ${ }^{2}$ School of Environmental Science and Engineering, Tiangong University, Tianjin 300387, China \\ "E-mail: wanglili@tjpu.edu.cn, bingwang@tjpu.edu.cn
}

doi: $10.20964 / 2020.03 .04$

Received: 4 October 2019 / Accepted: 9 December 2019 / Published: 10 February 2020

The construction of non-precious metal nanomaterial with higher sensitivity and better selectivity is very important for glucose detection. In this paper, three-dimensional (3D) hierarchical layered double hydroxide $(\mathrm{LDH})$ nanomaterials $(\mathrm{CC} @ \mathrm{CCH} \mathrm{NiFe} \mathrm{LDH})$ are successfully synthesized by simple hydrothermal method. 1D basic cobalt carbonate $(\mathrm{CCH})$ nanorods are preliminarily formed on the carbon cloth (CC), which acts as support, and then 2D NiFe LDH nanosheets are guided to deposit on the surface. Therefore, the hierarchical layered structure was obtained with high surface area and more active sites. The prepared CC@CCH NiFe LDH electrode material possesses excellent electrochemical catalytic oxidation performance. The test results show that the electrode material has high sensitivity $\left(6610 \mu \mathrm{A} \cdot \mathrm{mM}^{-1} \cdot \mathrm{cm}^{-2}\right)$, wide linear range $(0.01-1 \mathrm{mM})$, fast current response $(<10 \mathrm{~s})$ and low detection limit $(3 \mu \mathrm{M})$. Furthermore, the sensor material has good selectivity.

Keywords: Carbonized cotton cloth, 3D hierarchical layered structure, NiFe LDH nanosheets, nonenzymatic glucose detection

\section{FULL TEXT}

(C) 2020 The Authors. Published by ESG (www.electrochemsci.org). This article is an open access article distributed under the terms and conditions of the Creative Commons Attribution license (http://creativecommons.org/licenses/by/4.0/). 